\title{
Replication of micro-sized pillars in polypropylene using the extrusion coating process
}

Okulova, Nastasia; Johansen, Peter; Christensen, Lars; Taboryski, Rafael J.

Published in:

Microelectronic Engineering

Link to article, DOI:

10.1016/j.mee.2017.01.027

Publication date:

2017

Document Version

Peer reviewed version

Link back to DTU Orbit

Citation (APA):

Okulova, N., Johansen, P., Christensen, L., \& Taboryski, R. J. (2017). Replication of micro-sized pillars in polypropylene using the extrusion coating process. Microelectronic Engineering, 176, 54-57.

https://doi.org/10.1016/j.mee.2017.01.027

\section{General rights}

Copyright and moral rights for the publications made accessible in the public portal are retained by the authors and/or other copyright owners and it is a condition of accessing publications that users recognise and abide by the legal requirements associated with these rights.

- Users may download and print one copy of any publication from the public portal for the purpose of private study or research.

- You may not further distribute the material or use it for any profit-making activity or commercial gain

- You may freely distribute the URL identifying the publication in the public portal

If you believe that this document breaches copyright please contact us providing details, and we will remove access to the work immediately and investigate your claim 


\title{
Replication of micro-sized pillars in polypropylene using the extrusion coating process
}

\author{
Nastasia Okulova ${ }^{a, b}$, Peter Johansen ${ }^{a}$, Lars Christensen ${ }^{a}$, Rafael Taboryski ${ }^{b}$ \\ aDanapak Flexibles A/S \\ Strudsbergsvej 3, \\ 4200 Slagelse, Denmark \\ ${ }^{\text {bDepartment }}$ of Nanotechnology, Technical University of Denmark \\ $\varnothing$ rsteds Plads, Bygning 345C, \\ 2800 Kgs. Lyngby, Denmark \\ E-mail addresses for each author in the same order as they are listed above. \\ nasok@nanotech.dtu.dk, pjo@danapakflex.com, lc@danapakflex.com, rata@nanotech.dtu.dk
}

Corresponding author:

Nastasia Okulova (nasok@nanotech.dtu.dk)

\begin{abstract}
A recent advancement in nano-pattern replication using roll-to-roll extrusion coating (R2R-EC) shows potential for many biomimetic applications. For further development of the technique a study of the micro-replication regime is executed. In this study a full and partial replication in polypropylene (PP) of micro-sized pillars has been demonstrated using the extrusion coating process. The replication fidelity of the pillars is investigated in a systematic variation of different process parameters: the line-speed of the rolls, the extruder output, the cooling roll temperature and the pressure on the cooling roll. The parameter making biggest impact on the replication is the temperature of the cooling roll.

The micro-sized pillars show replication behavior opposite to what was found previously for the nano-patterns. The larger structures take the time to fill in and replicate best at the lower speeds. In this article a direct comparison of the speed at the same coating thickness is conducted.
\end{abstract}

\section{Keywords}

Roll-to-Roll Fabrication, Extrusion Coating, Polymer Micro Structures, Polypropylene, DEEMO

Process, Bosch Process 


\section{Introduction}

The roll-to-roll extrusion coating process ${ }^{1}$ shows promising results in terms of the reproducibility and the quality of the replicated patterns ${ }^{2,3}$. The technique has potential for production of hundreds of meters in length of structured foil with web width up to $3 \mathrm{~m}$, and thus allows numerous options for large scale production of biomimetic structures ${ }^{4}$. The production speed can be up to $1000 \mathrm{~m} / \mathrm{min}$ and the possibility to implement the foil structuring directly into the existing technology without modifying the underlying method or the used materials makes extrusion coating the fastest known method for production of patterned foils.

The micro- and nano-structured foil sheets have a wide range of potential applications for selfcleaning surfaces for external use ${ }^{5}$, as anti-icing structures ${ }^{6}$ for anti-reflective ${ }^{7}$ surfaces on windows, etc. The applications possibilities are endless, however it is important to understand the replication process, investigate its parameters and understand the limitations of this method. While the replication of nano-grass structures in PP with a hydrophobic effect was studied by Telecka et al. ${ }^{8}$, an investigation of the replication of micro-patterns can lead us one step further towards building hierarchical structures for superhydrophobic self-cleaning foils.

A previously conducted systematic study on the nano-sized structures ${ }^{2}$ pointed out the important parameters for nano-replication: the temperature of the cooling roll, the nip pressure and the line speed during the production of the extruded material. A different behavior was observed for the micro-sized structures, and is the main motivation for the systematically studied replication regime for the micro-pillars.

In this study four different extrusion-coating parameters are varied in order to understand the impact of each parameter on the shape of the produced pillars. The production line speed is an important factor in the replication of the nano-sized patterns. It is important to notice that the coating layer varies with the line speed, and the thickness plays an important role when it comes to the micro-sized structures. In this study the line speed is matched with the extruder output to see the impact of the production speed on the replication within the same thickness of the coating layer.

The temperature of the cooling roll and pressure on the cooling roll appeared to be important factors for replication of nano-sized structures, and are investigated further in this study. During the replication of micro-sized structures, the temperature of the cooling roll is expected to have the biggest impact on the quality of the produced foil.

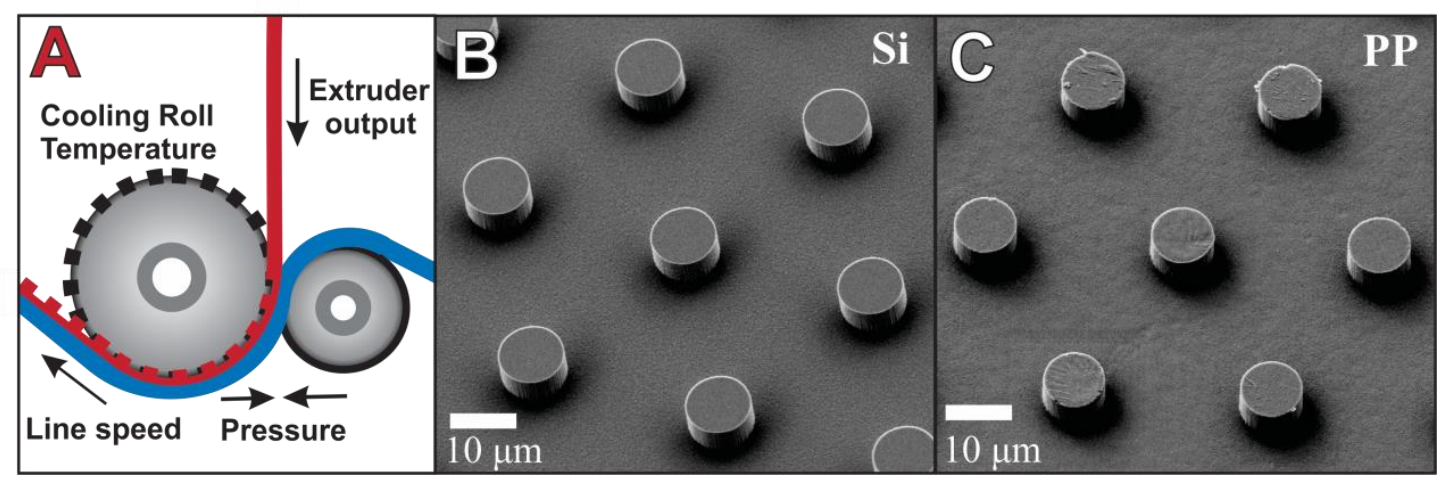


Figure 1. The replication process:

A. A schematic representation of the parameters varied in this study. B. Si master structure. $C$. The replica of the pattern in PP at $70^{\circ} \mathrm{C}$ of the cooling roll, line speed of $10 \mathrm{~m} / \mathrm{min}$, pressure of $20 \mathrm{bar}$ and extruder output of $450 \mathrm{~g} / \mathrm{min}$.

\section{Experimental}

The extrusion coating process is done at a pilot production line at Danapak Flexibles $\mathrm{A} / \mathrm{S}$. The process is described in detail in ${ }^{2}$. A variation of the following four process parameters is presented in this article. The $36 \mu \mathrm{m}$ PET foil is used as a carrier foil and the tie-melt and polypropylene-melt are co-extruded onto the carrier foil at 90,270 and $450 \mathrm{~g} / \mathrm{min}$ output speeds at 10,30 and 50 $\mathrm{m} / \mathrm{min}$ line speeds. The extruder outputs are varied in order to test the influence of the extrusion speed at the same thickness of the extruded layer. Additionally, the influence of the pressure on the cooling roll (hydraulic pressure of 10 and 20 bar) and the temperatures of 15,40 and $70^{\circ} \mathrm{C}$ of the cooling roll are tested as well. The varied parameters are indicated in the schematic in Figure $1 \mathrm{~A}$, where the incoming polymer melt is indicated with red, the blue line is the carrier foil and the cooling roll in the middle is marked with black square shapes indicating the micro-structured shims attached to the roll using an adhesive.

The details of the shim fabrication are given in references ${ }^{9-11}$, but in short, $100 \mathrm{~mm}$ Si wafers were spin coated (SSE Spinner, Maximus 804) with positive tone resist (AZ512E), and patterned by photolithography (SUSS Mask Aligner MA6) using a mask of $10 \mu \mathrm{m}$ diameter spots and developed for $60 \mathrm{~s}$ (AZ 351B developer). The patterns were then etched using DRIE (Pegasus DRIE, STS. MP0636) to a depth of $5 \mu \mathrm{m}$ using a standard Bosch process, and the excess photoresist was removed by plasma ashing directly in the DRIE machine. Subsequently the Si wafers were coated with a $70 \mathrm{~nm}$ NiV seed metal layer (Lesker CMS 18 sputter system). A $230 \mu \mathrm{m}$ thick Ni shim was electroformed (Microform 200, Technotrans) with a negative relief. The Si was removed by wet etching in $75^{\circ} \mathrm{C} \mathrm{KOH}$ solution and the Ni shim was coated with FDTS (MVD100E, Applied Microstructures Inc.). The master structure fabrication and production of the Ni shim were performed at DTU Danchip cleanroom facility. An example of a Si master structure is shown in Figure 1B, whereas the replica in PP is shown in Figure $1 \mathrm{C}$.

The produced foils were cut out and covered with a 10nm layer of Au for scanning electron microscopy (SEM) characterization. The filling and the shrinkage of the structures were estimated using $30^{\circ}$ tilted view SEM (Supra 4OVP SEM). The results of these measurements are presented in the next section.

\section{Results and discussion}

The production line speed was previously shown to have a large impact on the replication fidelity of nano-sized structures ${ }^{2}$. However, varying the line speed at a fixed extruder output results in varying coating thickness. The typical coating thickness is between 3 and $100 \mu \mathrm{m}$ and are within the same range as the depth of the replicated structures. The coating thickness is thus an important factor for the replication of the micro-pillars, especially at the higher speeds when the coating thickness is low.

The layer thickness is linearly proportional to the extruder output and the line speed, while the effects of the pressure and the temperature on the layer thickness are negligible. In Figure 2 the results from three extruder outputs for three line speeds are presented. Four sketches of the 
$\mathrm{Ni} / \mathrm{PP} / \mathrm{PET}$ stack during the replication process indicate how the line speed and the extruder output influence the thickness of the extruded layer, ranging from $4 \mu \mathrm{m}$ coating layer at $90 \mathrm{~g} / \mathrm{min}$ and $50 \mathrm{~m} / \mathrm{min}$ to $75 \mu \mathrm{m}$ layer at $450 \mathrm{~g} / \mathrm{min}$ and $10 \mathrm{~m} / \mathrm{min}$. The relative size of the pillar cavities in the stamp and the layer thickness in the sketches are to scale.

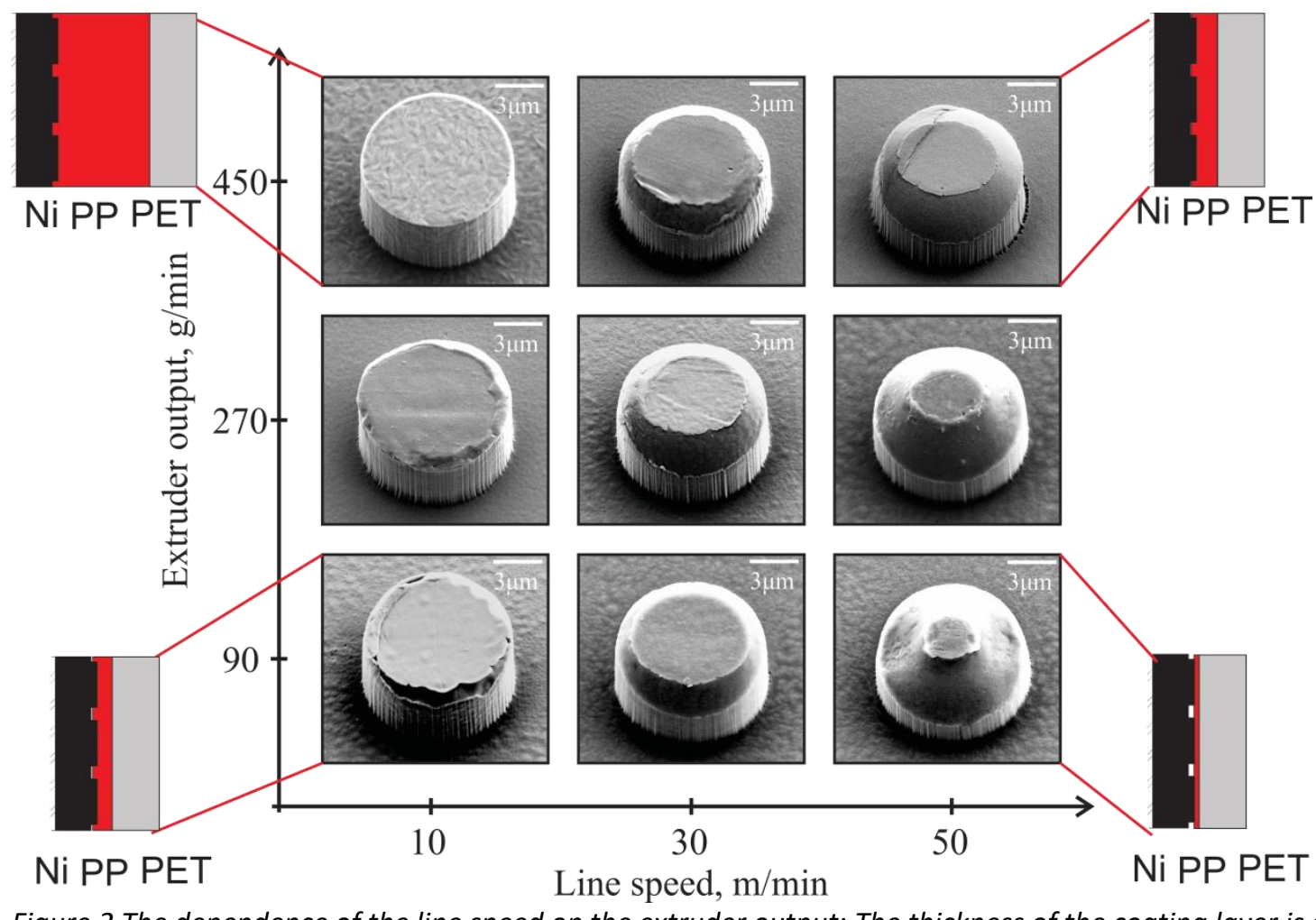

Figure 2 The dependence of the line speed on the extruder output: The thickness of the coating layer is comparable in $10 \mathrm{~m} / \mathrm{min}$ at $90 \mathrm{~g} / \mathrm{min}, 30 \mathrm{~m} / \mathrm{min}$ at $270 \mathrm{~g} / \mathrm{min}$ and $50 \mathrm{~m} / \mathrm{min}$ at $450 \mathrm{~g} / \mathrm{min}$. The replication gets worse with higher speeds at the same thickness. The output seems to influence the process the most at higher speeds where the thickness becomes comparable to the height of the pillars, which results in worse replication. Temperature of the cooling roll is kept at $70^{\circ} \mathrm{C}$, the hydraulic pressure is $20 \mathrm{bar}$ for all results in this figure.

Unlike the nano-sized structures shown in Murthy et al. ${ }^{2}$ and Telecka et al. ${ }^{8}$, the micro-pillars replicate best at lower speeds. As seen in Figure 2, in the diagonal direction, where the thickness is kept constant, the velocity still has a negative impact on the filling. Here a different filling regime applies. The filling is not driven by the surface tension of the polymer melt as for nano-structures, but rather by the viscoelastic flow.

In Figure 3A the volume of the PP structures compared to the volume of the original master structure is presented in terms of percentage at 3 different cooling roll temperatures. The polymer melt cools down less rapidly at the higher temperatures of the cooling roll; hence polypropylene has more time to flow into the cavities. As expected, the temperature of the cooling roll does influence the replication fidelity more than any other factor, within the given parameter range.

The pressure on the cooling roll does not have as large impact on the filling of the micro-pillars, as seen in Figure 3B, compared to the impact the pressure has on the replication of the nano-pillars. This result needs further investigation, since both shown examples in Figure 3B are of pillars with a 
high filling, where the polymer melt has touched the bottom of the cylindrical mold. Taylor ${ }^{12}$ simulates for the hot embossing process, that the filling is not governed as much by a change in pressure after the melt has touched the bottom of the mold (Figure 4 in Taylor ${ }^{12}$ ). If the extrusion coating process is undergoing the same processes, a further investigation of less-filled structures is needed to draw a definite conclusion on this matter.
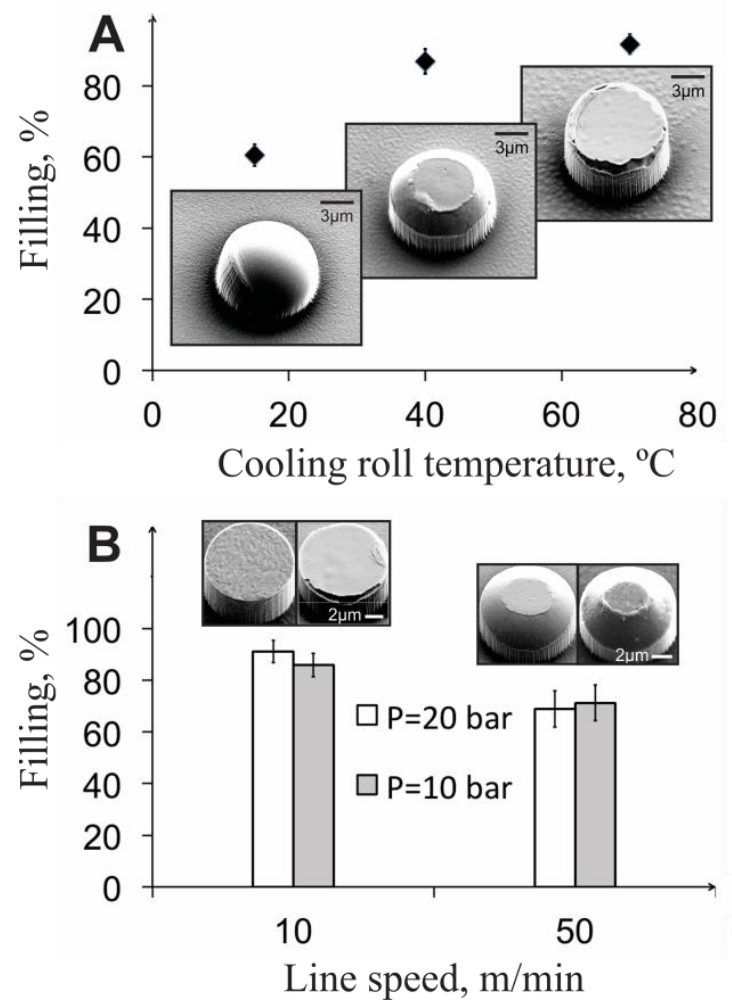

Figure 3. The influence of the temperature and the pressure: A. The volume percentage of the original structure are plotted as a function of the temperature of the cooling roll. The replication fidelity is not close to $100 \%$ due to the shrinkage. The patterns are clearly better replicated at the higher temperatures. All other parameters are kept constant: 20 bar pressure on the cooling roll, $10 \mathrm{~m} / \mathrm{min}$ line speed and $90 \mathrm{~g} / \mathrm{min}$ extruder output. $B$. The results at two different pressure values are shown in this graph. The pressure of 10 and 20 bar is compared at two different line speeds and the pressure does not seem to have a large impact on the replication fidelity. For these samples, temperature of the cooling roll was kept at $70^{\circ} \mathrm{C}$, the extruder output at $450 \mathrm{~g} / \mathrm{min}$.

The PP pillars seem to have a smaller size than the original Si master structures. Some shrink in the lateral direction is observed in all the resulting pillars, however the numerical values vary between 2 and $8 \%$ and no apparent tendencies can yet be extracted. The typical shrink values for injection molding with PP lie

around $0.5-2 \%{ }^{13}$, which indicates that the extrusion coating process induces additional strain. Gershon et.al. suggests that the difference between the rapid cooling on the surface of the polymer close to the mold and the opposite side of the melt not in contact with the shim surface could give rise to strain ${ }^{14}$.

Semi crystalline polymers like polypropylene have a higher shrinkage rates than the amorphous polymers, due to the packing in crystalline regions. The crystallinity is correlated with the cooling rate; hence the temperatures at which the polymer is handled are important. The investigated extrusion coating parameters should have an influence on the shrinkage. For the injection molding Gipson et.al. determined the shrinkage rate to decrease with increase in cavity pressure and melt temperature. At the same time shrinkage increases with higher mold temperature and higher polymer thickness ${ }^{13}$.

The fact that the scallops from the Bosch process are replicated perfectly in the polymer (see Error! Reference source not found.Figure 4) shows that the pillars indeed do shrink in the lateral direction, otherwise the structure would not come out of the mold intact. This gives rise to a possibility of manufacturing re-entrance structures with a variation in the horizontal direction of up to $8 \%$ for PP. 


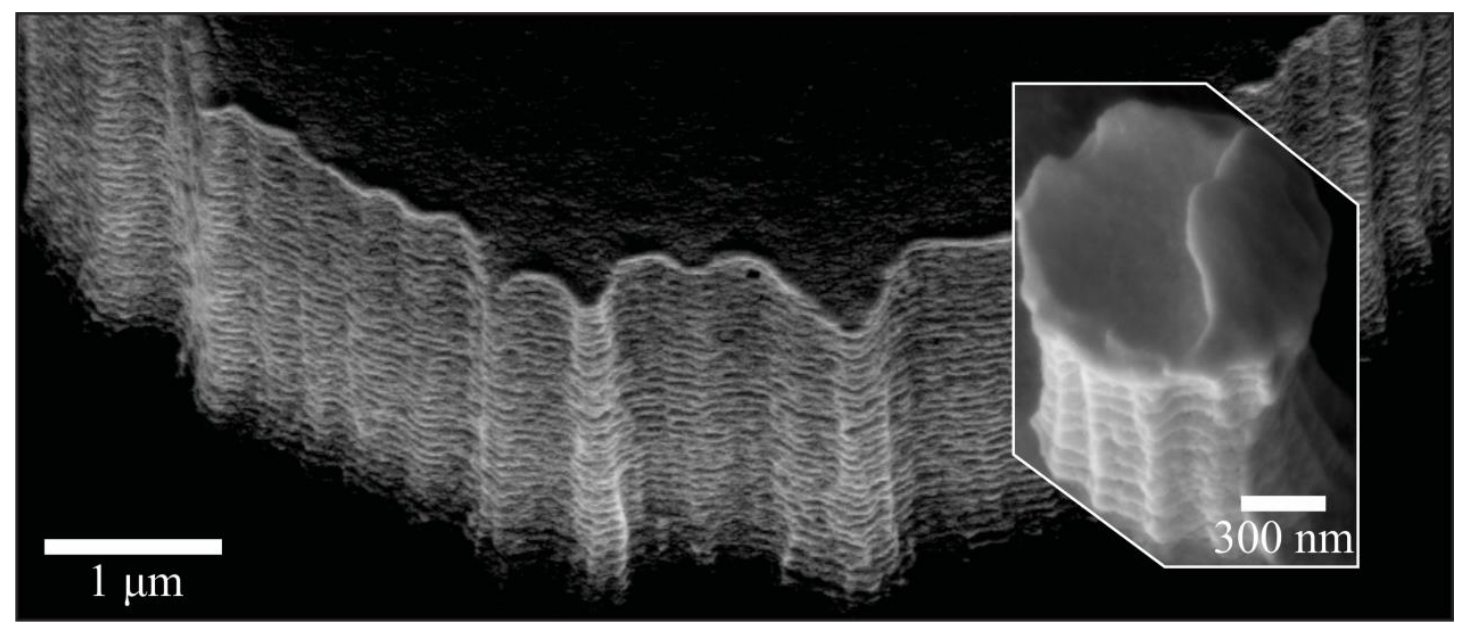

Figure 4. The Bosch scallops replicated in PP. In the insert we show a smaller pillar with visible scallops.

This technology constitutes a novel general fabrication platform for micro- and nanotechnology, by allowing reliable replication on both micro- and nanoscale of complicated patterns. We thus foresee applications within large area fabrication of textured functional surfaces, and within the design of bio-sensors and lab-on-chip systems to be used in the fields of chemistry, biology, and medicine, where a flexible form-factor is required for the devices.

\section{Conclusions and outlook}

Results for replication of micro pillars in PP have been demonstrated, with a range of $50-90 \%$ replication of the initial pattern. The most impactful parameter on the replication fidelity is the temperature of the cooling roll, and as demonstrated in a previous study for the nano-sized structures, a $70^{\circ} \mathrm{C}$ cooling roll gives the best results for the pattern replication. Surprisingly, the pressure on the cooling roll did not seem to have much impact on the replication fidelity of the micro patterns.

Opposite to the nano-pillar replication, the micro pillars are replicated best at the lower line speeds, which indicates that another regime including considerably higher polymer melt flow is involved in this process, calling for a further theoretical investigation of this replication regime as well as finding the overlap between the micro- and nano-regimes.

A lateral shrinkage of the PP pillars is observed and shows a promising platform for building reentrance structures with larger features in the lateral direction, such as $t$-shapes ${ }^{15}$ for production of omniphobic structures ${ }^{16}$. Combining the results for the micro-sized structures and nano-sized structures, hierarchical structures ${ }^{17}$ for hydrophobic purposes can be investigated as well.

Polypropylene does show promising results for micro-replication, however many other polymers are used in packaging production and the possibility for using those polymers and the effect of polymer crystallinity also calls for further studies.

\section{Acknowledgements}


Special thanks to the Danapak staff for help with running the extrusion coating, to the Polymic research group for fruitful discussions, to Anton Kovyakh for proof-reading the article.

\section{Funding}

This work was supported by the Innovation Fund Denmark through the project XNano [grant number 4135-00142B].

1. C. Sollogoub, E. Felder, Y. Dernay, J. F. Agassant, P. Deparis and N. Mikler, Polymer Engineering and Science 48 (8), 1634-1648 (2008).

2. S. Murthy, M. Matschuk, Q. Huang, N. K. Mandsberg, N. A. Feidenhans'l, P. Johansen, L. Christensen, H. Pranov, G. Kofod, H. C. Pedersen, O. Hassager and R. Taboryski, Advanced Engineering Materials 18 (4), 484-489 (2016).

$3 . \quad$ S. Murthy, H. Pranov, H. C. Pedersen and R. Taboryski, Journal of Vacuum Science \& Technology B 34 (6), 06KM02 (2016).

4. B. Bhushan, Philosophical Transactions of the Royal Society a-Mathematical Physical and Engineering Sciences 367 (1893), 1445-1486 (2009).

5. $\quad$ R. Blossey, Nature Materials 2 (5), 301-306 (2003).

$6 . \quad$ J. B. Boreyko, B. R. Srijanto, T. D. Nguyen, C. Vega, M. Fuentes-Cabrera and C. P. Collier, Langmuir 29 (30), 9516-9524 (2013).

$7 . \quad$ K. Choi, S. H. Park, Y. M. Song, Y. T. Lee, C. K. Hwangbo, H. Yang and H. S. Lee, Advanced Materials 22 (33), 3713-+ (2010).

$8 . \quad$ A. Telecka, S. Murthy, L. Schneider, H. Pranov and R. Taboryski, ACS Macro Letters, 1034-1038 (2016).

9. N. K. Andersen and R. Taboryski, Microelectronic Engineering 141, 211-214

(2015).

10. J. Elders, H. V. Jansen, M. Elwenspoek, W. Ehrfeld and Ieee, DEEMO: A new technology for the fabrication of microstructures. (1995).

11. S. Tanzi, P. F. Ostergaard, M. Matteucci, T. L. Christiansen, J. Cech, R. Marie and R. Taboryski, Journal of Micromechanics and Microengineering 22 (11) (2012).

12. H. Taylor, M. Hale, Y. C. Lam and D. Boning, Journal of Micromechanics and Microengineering 20 (6) (2010).

13. P. M. Gipson, P. F. Grelle, B. A. Salamon and E. Soc Plast, Antec '99: Plastics Bridging the Millennia, Conference Proceedings, Vols I-Iii: Vol I: Processing; Vol Ii: Materials; Vol Iii: Special Areas; , 443-449 (1999).

14. A. L. Gershon, L. S. Gyger, H. A. Bruck and S. K. Gupta, Experimental Mechanics 48 (6), 789-798 (2008).

15. A. F. Chen and H. X. Huang, Journal of Physical Chemistry C 120 (3), 1556-1561

(2016).

16. R. Hensel, C. Neinhuis and C. Werner, Chemical Society Reviews 45 (2), 323-341

(2016).

$17 . \quad$ E. Sogaard, N. K. Andersen, K. Smistrup, S. T. Larsen, L. Sun and R. Taboryski, Langmuir 30 (43), 12960-12968 (2014). 